\title{
Where Should Existing Video Streaming Platforms Improve: A Comparative Analysis of Netflix and IQiyi
}

\author{
Yiyun Huang ${ }^{1, *}{ }^{*} \dagger$ Zeyuan $\mathrm{Lv}^{2, \dagger}$ Zhenyuan Sui ${ }^{3, \dagger}$ \\ ${ }^{1}$ College of Foreign Languages and Literature, Fudan University, 200433, Shanghai, China \\ ${ }^{2}$ Annenberg School for Communication and Journalism, University of Southern California, 90089, Los Angeles, CA, \\ USA \\ ${ }^{3}$ College of Humanities and foreign languages, Qingdao University of Technology, 266525, Qingdao, China \\ *Corresponding author. Email: 19300120031@fudan.edu.cn \\ These authors contributed equally.
}

\begin{abstract}
This study investigates two video streaming giants, Netflix and IQiyi, resorting to finding where they should improve through analyzing financial reports and the review comments from both of its apps. Statistical analysis and a deep textmining method have been applied accordingly. Findings from financial reports reveal that Netflix has more potential in its diversification of revenue streams, and IQiyi should enlarge its business scale. Text-mining results demonstrate that both platforms need to improve in the fields of content and app features. Netflix should find ways to maintain and continue its high-quality series content, while IQiyi should expand its content library. Both platforms should work on technical problems, among which Netflix can also improve in features of personalized lists and subtitles. In addition, the subscription issue remains to be a significant problem for IQiyi, including the high price, too many layers of payment, and auto-renewal contract system. This research offers an alternative approach and a more coherent understanding of Netflix and IQiyi's deficiencies. Methodologically, it further contributes by illustrating how review comments could be effectively applied in video-streaming related studies.
\end{abstract}

Keywords: Netflix, IQiyi, video streaming, text mining.

\section{INTRODUCTION}

As people's preference for media forms has changed from text, images, audio, video, and live broadcasting to the current short-term video [1], short video development has become the general trend. Since short video platforms as TikTok have gained global momentum [2] with their interactive social networking feature and its easy-to-use video editing tools, the industry in the future will become the key hub of interdisciplinary connectivity and integration [3], therefore posing a threat to the longexisting video streaming giants including Netflix, YouTube, and other incumbent streaming giants. This article focuses on two streaming platforms: Netflix and IQiyi, with the former being the world's largest subscription-based video streaming company and the latter being a leading video streaming platform in mainland China.

Previous studies have investigated each of the platforms individually. Existing case studies of IQiyi have examined the local head runner's commercial success, which can be attributed to its ability to cater to the desires of preferred customers and its gaining of promotion from the government [4]. While Netflix, as a global OTT video streaming service, is securing a content library and utilizing the value of internal resources and the diversity of content as a strategy to enter the global market [5]. Research has also revealed strategy-oriented implications for video streaming platforms based on customers' preferences. For example, Asian consumers somehow show a less understanding that content deserves to be purchased, therefore revealing a lower willingness to pay than US or European consumers [6]. Meanwhile, as the price has long ranked the highest among unsatisfactory items in media services [7], pricing strategies should be adjusted accordingly. In addition, more studies have focused on local penetration of global OTT services like Netflix and YouTube [8], accentuating the negative impact of global OTT service have on local video industries proved by cases of Thailand [9] and Brazil [10]. However, only a few studies have yielded discussion from the perspective of consumers. Though 
studies have probed into consumers' viewing habits [11], few studies to date have examined specific comments from streaming platform apps. Meanwhile, less previous evidence has considered a comparative analysis between two specific streaming platforms, including one global and one local service in a parallel manner. Filling the analysis gap between Netflix and iQiyi is important for both companies to develop and advance more into the global market. Without such comparative analysis between the two companies, the gap between the streaming platforms of China and those of the rest of the world will not be filled.

This paper aims to provide insight into the existing problems and also identify some of their strengths in current leading video streaming platforms. To comprehend a complete and comprehensive understanding of video streaming platforms, this paper utilizes a comparative analysis between Netflix, a global streaming service, and IQiyi, a local streaming giant in China. One major approach proposed in this article is applying text mining based on the review comments of the platforms' app. While combing with the statistical analysis of the financial reports, this study found specific issues of concern of each app from consumers' perspective, including problems related to subscription, content, and app features. The project hopes to ultimately contribute to helping streaming service providers effectively provide better services that are more catering to consumers' needs.

\section{NETFLIX AND IQIYI}

Netflix is an American over-the-top content platform and production company headquartered in Los Gatos, California. The company's primary business is a subscription-based streaming service offering online streaming from a library of films and television series, including those produced in-house [12]. By 2020, Netflix has become the largest entertainment and media company by market capitalization [13] and the largest global streaming platform.

IQiyi is a Chinese online video platform based in Beijing launched on April 22, 2010. IQiyi is currently one of the largest online video sites globally, with nearly 6 billion hours spent on its service each month and over 500 million monthly active users [14]. On March 29, 2018 , the company issued its IPO in the U.S. and raised $\$ 2.25$ billion [15].

\section{RESEARCH DESIGN}

\subsection{Data collection}

In this study, we refer to two main information sources: financial reports of respective sides and review comments from each of its apps.
The importance of a financial report lies in its cohesive break-down demonstration of crucial financial information that enables a comprehensive analysis of the corporation. Such analysis, therefore, facilitates outsiders to make accurate projections based on past or emerging trends and propose better future strategies for this company[16]. In this study, we referred to the annual financial statements of Netflix and IQiyi in the year 2020 and 2019. The annual financial reports were obtained from corporations' official websites [17, 18], and all the data information contained is officially transparent and free to download. Specific segments of data included in financial reports were extracted considering both corporations' total revenue, revenue streams, members of the subscription cost, etc.

The significance of online review comments mainly lies in their usefulness in identifying users' experience and its links to the firm's performance and social practices creating unique insights for both researchers and practitioners [19]. An extraction of review comments tending to voice opinions provides insight from the customers' sides to evaluate corporations' attractiveness to their targeted market. The review data set in this paper was obtained from the app store Ratings \& Reviews session of Netflix and IQiyi applications. The former was obtained using a US app store account and the latter with a Chinese account since US/China is Netflix/IQiyi's primary market accordingly. The reviews were selected within a month, from June 11th, 2021, to July 10th, 2021, with a total of 645 comments for Netflix and 656 comments for IQiyi. The review comments are publicly accessible.

\subsection{Data analysis}

Two stages were involved in the data analysis. In the first stage, a comparison regarding financial performance was performed based on the financial reports. Two indicators--revenue streams and subscription membership were compared separately between Netflix and IQiyi. In the second stage, text-mining results were utilized as evidence, and three themes were identified as issues of concern for both platforms: subscription, content, and app features. Under each theme, specific highly-reported issues were listed for each platform. In addition, one or two detailed comments were also demonstrated for reference under each categorization. 


\section{FINDINGS}

\subsection{Financial performance}

\subsubsection{Revenue \& revenue distribution}

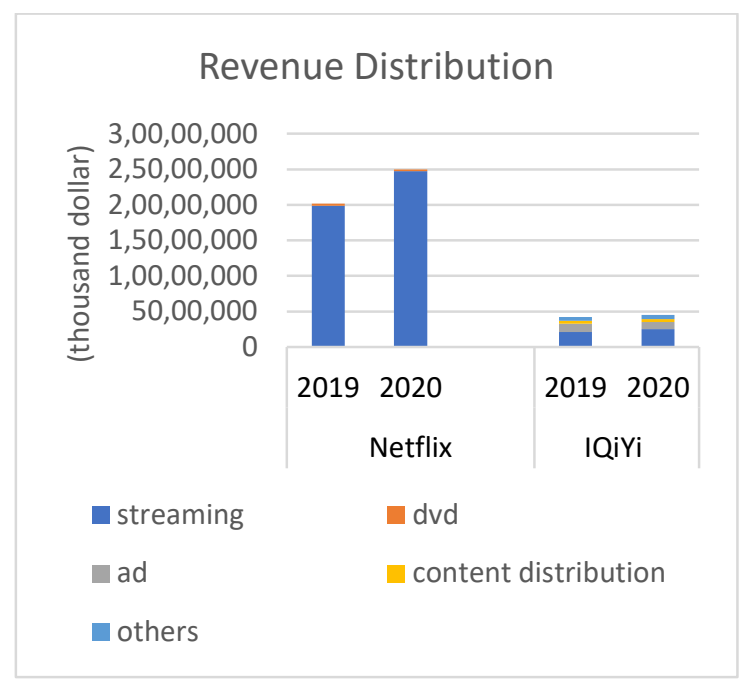

Figure 1. Revenue distribution of Netflix and IQiyi

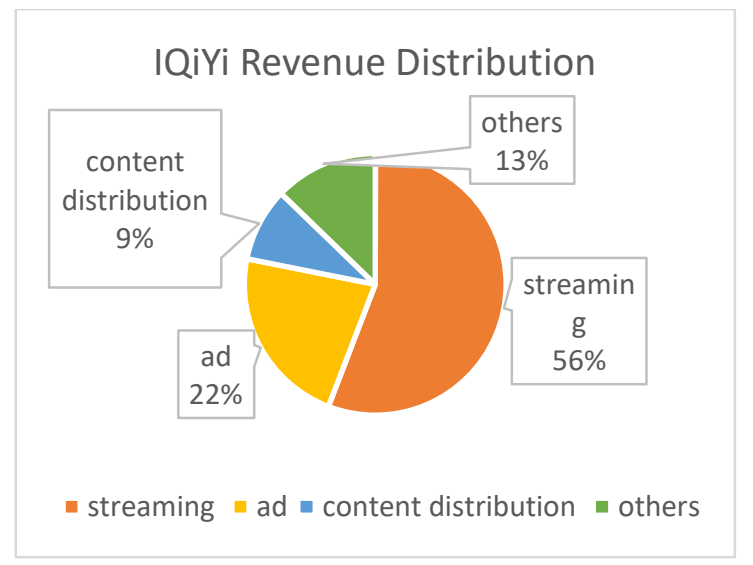

Figure 2. Revenue distribution of IQiyi

Figure 1 shows the revenue status of Netflix and IQiyi with a major focus on revenue distribution in the years 2019 and 2020. Both companies are financially improving individually, while Netflix surpasses IQiyi in both revenue scale and profitability.

Netflix derives its revenue from two streams: its mainstreaming service and its original DVD service, among which streaming services account for nearly $99 \%$ of the total revenue. Its streaming revenue increases $25 \%$ from $\$ 19$ billion in 2019 to $\$ 24$ billion in 2020, while its original DVD service has dropped from \$297 million in 2019 to 239 million dollars in 2020, which is a $19 \%$ decrease. While the revenue distribution for IQiyi is rather diversified and consists of four parts: subscription streaming service, advertising, content distribution, and others. Like Netflix, subscription revenue is the company's biggest revenue stream, while a considerable amount of online advertising revenue is the secondlargest component of IQiyi's total revenue. Internal overall revenue distribution of IQiyi is displayed in Figure 2, demonstrating 56\% from subscriptions, $22 \%$ from online ads, $9 \%$ from content distribution to other platforms or TV channels, and 13\% from other revenues.

Overall, the revenue distribution of Netflix and IQiyi is quite different, with IQiyi owning a more diversified revenue stream. However, both corporations generate the most of their revenue from subscription streaming services.

\subsubsection{Subscription}

According to the financial statements $[17,18]$, at the end of 2020, Netflix has approximately 204 million paid memberships, gaining over 36 million new subscribers over the year. From 2016 on, the number of paid subscriptions to Netflix has been steadily increasing, with a number of over 18 million annually. At the end of 2020 , IQiyi has over 10 million paid memberships. Meanwhile, with the core strategy of expanding globally for its subscription service, from 2018 to 2020 , Netflix has been gaining around 30 million new subscriptions globally each year. By 2020, Netflix has generated revenue of over $\$ 11$ billion in the US and Canada, \$7 billion in Europe, the Middle East, and Africa, \$3 billion in Latin America, and $\$ 2$ billion in Asia-Pacific. While IQiyi has gained over $\$ 10$ million from paid services over the year of 2020, mainly due to the increase in paid membership.

Netflix's main source of revenue is paid memberships. Although IQiyi also generates more revenue from paid subscriptions, it offers a range of free services and generates revenues from various sources. Thus, IQiyi generates significantly less revenue from paid memberships than Netflix does.

Table 1. Likelihood of keywords in Netflix's review

\begin{tabular}{lcc}
\hline Keywords & Count & \multicolumn{2}{c}{ Likelihood } \\
\hline app & 207 & $32.09 \%$ \\
movie & 196 & $30.39 \%$ \\
season & 138 & $21.40 \%$ \\
love & 112 & $17.36 \%$ \\
cancel & 88 & $13.64 \%$ \\
TV & 62 & $9.61 \%$ \\
anime & 60 & $9.30 \%$ \\
episode & 53 & $8.22 \%$ \\
remove & 40 & $6.20 \%$ \\
download & 37 & $5.74 \%$ \\
amazing & 36 & $5.58 \%$ \\
series & 36 & $5.58 \%$
\end{tabular}




\begin{tabular}{lll} 
star & 35 & $5.43 \%$ \\
phone & 33 & $5.12 \%$ \\
account & 33 & $5.12 \%$ \\
$\log$ & 32 & $4.96 \%$ \\
sign & 29 & $4.50 \%$ \\
content & 26 & $4.03 \%$ \\
screen & 25 & $3.88 \%$ \\
service & 24 & $3.72 \%$ \\
\hline
\end{tabular}

Table 2. Likelihood of keywords in IQiYi's review

\begin{tabular}{|c|c|c|}
\hline Keywords & Count & Likelihood \\
\hline VIP & 239 & $36.43 \%$ \\
\hline advertisements & 174 & $26.52 \%$ \\
\hline trash & 114 & $17.38 \%$ \\
\hline app & 77 & $11.74 \%$ \\
\hline video & 70 & $10.67 \%$ \\
\hline charge & 58 & $8.84 \%$ \\
\hline bad & 51 & $7.77 \%$ \\
\hline movie & 47 & $7.16 \%$ \\
\hline projection & 30 & $4.57 \%$ \\
\hline disgusting & 29 & $4.42 \%$ \\
\hline update & 27 & $4.12 \%$ \\
\hline TV series & 27 & $4.12 \%$ \\
\hline renewal & 26 & $3.96 \%$ \\
\hline Tengxun & 24 & $3.66 \%$ \\
\hline crash & 24 & $3.66 \%$ \\
\hline download & 23 & $3.51 \%$ \\
\hline automatic & 22 & $3.35 \%$ \\
\hline phone & 22 & $3.35 \%$ \\
\hline cancel & 17 & $2.59 \%$ \\
\hline anime & 16 & $2.44 \%$ \\
\hline
\end{tabular}

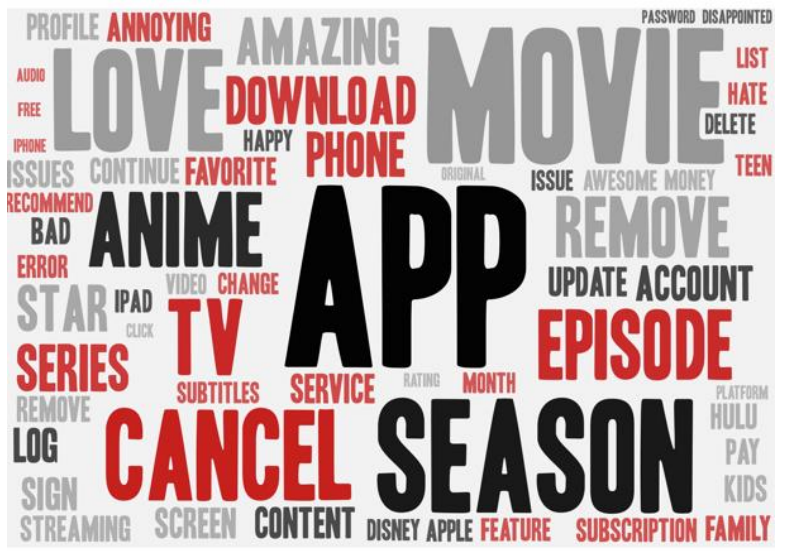

Figure 3. Word cloud based on Netflix's review

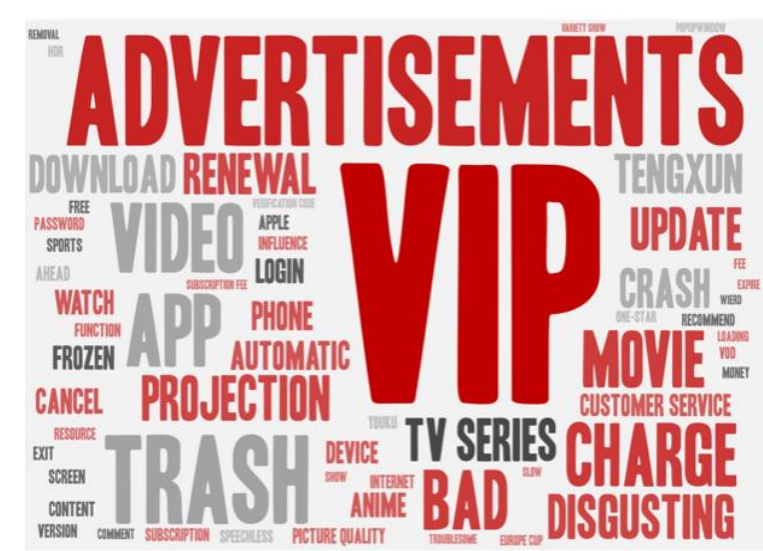

Figure 4. Word cloud based on IQiyi's review

\subsection{Text-mining results}

A deep text-mining analysis based on the review comments was utilized, and high-frequent words appeared in each of the platform app's review were further extracted. Due to the limitation of the paper, Table 1 and Table 2 demonstrates the top 20 words frequently mentioned in the review comments. While Figure 3 and Figure 4 are two visualized word clouds depicted based on the words extracted.

\subsubsection{Subscription issues}

\subsubsection{Netflix-availability}

Based on the review, Netflix allows its users to have the service on $1 / 2 / 4$ device(s) simultaneously with basic/standard/premium plans accordingly which have gained prevalent satisfaction from users. Once subscribed, users have access to unlimited TV shows and movies that Netflix offers. The Netflix application can be downloaded on any device free. Users can cancel their subscriptions at any time. 


\subsubsection{Netflix-no advertisements}

One of the main differences between Netflix's and iQiyi's services is that Netflix does not generate revenue from advertisements. Advertisements and sponsorships are some of the main sources of revenue for streaming platforms. However, to provide a better customer experience, Netflix has not adopted advertisements for its videos.

\subsubsection{IQiyi-price}

A major concern is the price of membership far exceeding consumers' willingness to pay when mentioning the VIP service of IQiyi in the review. Different hierarchies of VIP were manifested as one of the complaining points where more money is required to be paid from consumers since IQiyi has a VIP classification system. For example, besides the VIP service, a star diamond membership service requires more payment for more content on the platform. Meanwhile, the advance on-demand service requires extra payment apart from the original subscription fee.

The company is becoming a veteran in cheating money. Originally VIPs can see the ad-free video, now there is an advanced on-demand service, and now comes a star diamond membership. Then what is the point in paying for the VIP?

\subsubsection{IQiyi-auto-renewal contract}

The auto-renewal contract was another issue of concern in the comments. Users reported that canceling this auto service is too complicated, and the platform simply generates money from users' disableness to cancel the service.

I didn't see the cancellation of the automatic renewal service. It collects my money at the end of each month.

\subsubsection{IQiyi-Advertising}

Advertising in terms of its excessiveness in amount and length and its embedment in basically everywhere of the app was largely complained in the review. For example, users still have to watch ads even when watching videos that have already been downloaded. Also, the various form of ads, such as some random popup ads, negatively influenced users' watching experience. Moreover, the fact that ads cannot be excluded even with a VIP service has also caused consumers' dissatisfaction.

I'm a V5 user. Why do I still have to bear your ads? Pause the video ads come out, play the video normally pop-up ads come out.

\subsubsection{Content issues}

Both Netflix and IQiyi pay attention to original content production. In recent years, Netflix attaches great importance to original content production, with more and more content providers starting to develop their own streaming services. Netflix reported in 2018 that $85 \%$ of new spending on content was going towards the creation of Netflix originals [20]. While facing many competitors such as Tencent, Youku, and IQiyi, they also stepped up the original production. However, in terms of actual output, Netflix's content quality outperforms those of IQiyi's, which is mainly due to the higher level of development of the global OTT industry in the United States. Global OTT services have built a great production environment and infrastructure based on huge capital [21]. Compared with Netflix, IQiyi pays more attention to providing diversified services considering its categories of content and its licensing businesses. The business scope of iQiyi's "apple tree" includes video, games, literature, etc., far exceeding the scale of most current video platforms, even Netflix. Further research has proved that diversified services provide more potential for a company's profit growth and ease the financial pressure brought by the production of original works [22].

\subsubsection{Netflix-cancelling/removal of content}

The cancelling of content was one of the most reported problems. According to the review of Netflix, the shows and series that have been removed were considered as content of high quality. A considerable number of viewers largely appreciated them. Thus the cancellation has triggered an overwhelming grumble reaction from users and hasn't attained general users' understanding.

In my opinion, I feel that you all cancel the good shows but keep the ones with low ratings, MAKE IT MAKE SENSE.

Moreover, Netflix has cancelled shows with educational values, consisting of actual revelations in real lives and relating with targeted viewers. Meanwhile, certain series that included representation of minorities were also on the list of cancellations, such as "grand army" showing representations of the person of color and series containing LGBTQ+ content, including "I am not okay with this" and "Atypical". The removal of these ultra-high-quality content and retaining similar content of the same genre have aroused common discontent among viewers.

Netflix, you cancelled grand army because "it didn't bring anything new to the teen genre," as if the kissing booth, to all the boys I've loved before, bring ANYTHING to the teen genre. Grand army was one of my favorite shows because it actually reveals real-life hardships and situations teens have to go through...This show was 
beautifully done, and in extremely disappointed for you once again cancelling an actual good show.

\subsubsection{Netflix-Discontinue in series shows}

The discontinuation in series shows that left many series unfinished have aroused widespread dissatisfaction. Comments have shown that many viewers ended up watching unfinished shows or were left with a cliff hanger. Users have doubted the intention of starting a series that will not be continued or will ultimately be canceled regardless of how popular it might be. Some thought Netflix should at least inform customers whether the show will continue or not in the first place to offer consumers a choice to watch it or not.

I've always enjoyed Netflix - until they started making a new series, then cancel it after one season. Over and over. Even if the shows get good attention and good ratings, why start anything new if it's only to get cancelled and who cares how many people love it?

\subsubsection{IQiyi-Limited content library}

In the comments, many audiences thought that the platform did not own many films and TV dramas, and many films also had copyright problems, which made the watching process troublesome. At the same time, many viewers reported that IQiyi's homemade dramas were of poor quality, and the stories were more old-fashioned. While for the company's own production, users complained that a large portion of them were idoloriented shows targeting attracting fans.

The aesthetic level is too low. Most of them are idoloriented dramas, and there are too few good dramas.

\subsubsection{IQiyi-animation}

In user comments, users found many problems when watching animation on IQiyi. for example, the watching process is not smooth enough, and the content library not big enough especially compared with other platforms. The audience also brought up the problem of the lack of Japanese original versions and subtitles.

No Japanese version? One piece has a Japanese version on other platforms.

\subsubsection{IOivi-up to date content}

Though the platform has generated discontent towards its content, IQiyi's keeping up with the latest trend has successfully satisfied users with its latest life for the European Championship.

I rated five stars mainly because I can see the European Championship.

\subsubsection{App features}

\subsubsection{Netflix-subtitles}

A more variety of subtitles, including Spanish, was raised as an issue of concern in comments because of Netflix's users' diversity in races. The app should then add more varied subtitles as both a response and demonstration of respect to the demand from viewers of different races.

Netflix USA should understand that it has many Latino viewers, and they would like to see more programs and movies in Spanish or at least with Spanish subtitles. There is less and less content in Spanish or with subtitles, and those that have suddenly appear only in English.

\subsubsection{Netflix-sortable personal list}

The app's missing feature of a sortable personalized list in its difficulty in filtering and ordering content and categories was another major technical issue in its comments. This directly disenables users to successfully sort out things they would like to watch and make the process become more complicated to use.

Why is it so difficult to allow your users to filter and sort the content by YEAR, genre, type? Why is it so difficult to allow me to exclude content that I already watched? Why is it so difficult to allow me to pin and order the categories the way I want?

\subsubsection{Netflix-technical issues}

Other technical problems include a too complicated navigation system, subscription payment methods that are not diverse, errors existing during the process of downloading and rewinding, discontinuation of videos when switching from one device to another, lack of features as spatial audio, and zooming wide content, etc.

Waste of time downloading, especially when in the middle of the downloaded movie it gets errors. Audio stops working or just freezes and won't play again, and then you would have to delete and redo it.

I love Netflix, but every time I watch it on another device like on my TV, I watch it and get 30 episodes or an hour passed on the movie or show, but when I watch it on my Xbox or phone, it doesn't resume where I was at.

\subsubsection{IQiyi-technical issues}

According to a deep analysis of IQiyi's review, technical issues consisting of projection bugs, frequent frozen or crash situations, WIFI connection issues is a major app theme being prominently brought up in IQiyi's review comments. Regarding projection, many users expressed their dissatisfaction towards the unusableness of this feature since situations of crashes and frozen always appear. At the same time, other platforms as 
Tengxun, Youku, Mangguo TV, the main competitors of IQiyi in the Chinese market, don't have such problems with their projection services. Moreover, consumers accused IQiyi of its bundled consumption when utilizing projection since the app requires purchasing another app owned by the company called qiyiguo TV to successfully install the entire service.

Other apps won't be cut off when they are projected on the screen with the same network and the same device. It's only IQiyi that cut off. Crash exists every ten seconds. The way that they want to sell their TV app is disgusting.

Junk software! I have paid for VIP, but the projection still freezes from time to time! You have to buy a kiwifruit TV from their company!! This is kidnapping consumption! Trash!

Apart from the issues mentioned above of concern extracted from the review comment, other issues as the rating system of Netflix and the kids-related issue of both sides have also been frequently raised in the comments. Users complained about the new rating system of Netflix, a system including only thumbs up and thumbs down, mainly due to its inefficacy in genuinely evaluating a show or movie as it is an entire unitary system. In addition, kids-related concerns were another major theme in the review of both sides. For both sides, users were generally content with the division of kids profile and adult profile. However, as mentioned in some reviews, kids' easy access to adult profiles requires the app for further improvements in more strict management of the kids' profile. Moreover, for Netflix, an unreasonable classification of age was another issue indicated by the comment. Many suggest not finding age-appropriate content since the app only includes two age sections: kids and adults. Thus, an intermediate section of teens is left out in the age categorization system, raising disappointment from those consumers.

\section{CONCLUSION}

Table 3 shows an overall integration of the issues we identify based on the analysis above. In the comparative analysis of Netflix and IQiyi, on the one hand, user comments on the respective app of both companies and their financial reports are studies to conclude that there are shared problems such as technical difficulties, for example, the improving the preciseness of personalized recommendations and subscription issues like simplification of the subscribing process and diversifying subscription plans. Meanwhile, there are more aspects that both companies need to learn from each other. Statistical analysis demonstrates that Netflix should continue to diversify its revenue streams, while IQiyi should focus on expanding its current business scale. On the other hand, deep text-mining showcases that both companies should continue to improve their services, especially content creation and application features, to improve the customer experience. Netflix should maintain and diversify its current content library, while IQiyi should focus on buying more copyrights and expanding its content library. In conclusion, this research article offers a more thorough understanding of Netflix and IQiyi's strengths and weaknesses. Methodologically, it offers an alternative approach to understanding how review comments could effectively be applied in videostream-related studies.

Table 3. Findings of Netflix and IQiyi based on four dimensions

\begin{tabular}{|c|c|c|c|c|}
\hline & $\begin{array}{l}\text { Financial } \\
\text { status }\end{array}$ & $\begin{array}{l}\text { Subscripti } \\
\text { on }\end{array}$ & Content & App \\
\hline \multirow[t]{3}{*}{$\begin{array}{l}\text { Netfl } \\
\text { ix }\end{array}$} & $\begin{array}{l}\text { Large } \\
\text { revenue } \\
\text { scale \& } \\
\text { profitabil } \\
\text { ity }\end{array}$ & $\begin{array}{l}\text { Significan } \\
\text { t paid } \\
\text { membersh } \\
\text { ips }\end{array}$ & $\begin{array}{l}\text { High- } \\
\text { quality } \\
\text { original } \\
\text { content }\end{array}$ & $\begin{array}{l}\text { Lack } \\
\text { subtitles }\end{array}$ \\
\hline & $\begin{array}{l}\text { Two } \\
\text { fixed } \\
\text { revenue } \\
\text { streams }\end{array}$ & $\begin{array}{l}\text { Availabili } \\
\text { ty on all } \\
\text { devices }\end{array}$ & $\begin{array}{l}\text { Canceling } \\
\text { of high- } \\
\text { quality } \\
\text { content }\end{array}$ & $\begin{array}{l}\text { Lack } \\
\text { sortable } \\
\text { personali } \\
\text { zed list }\end{array}$ \\
\hline & & No ad & $\begin{array}{l}\text { Discontinu } \\
\text { e in series } \\
\text { shows }\end{array}$ & $\begin{array}{l}\text { Technical } \\
\text { problems }\end{array}$ \\
\hline \multirow[t]{2}{*}{ IQiyi } & $\begin{array}{l}\text { Overall } \\
\text { improvin } \\
\text { g but } \\
\text { falls } \\
\text { behind } \\
\text { that of } \\
\text { Netflix } \\
\text { Diversifi } \\
\text { ed } \\
\text { revenue } \\
\text { streams }\end{array}$ & $\begin{array}{l}\text { Price too } \\
\text { high \& } \\
\text { too many } \\
\text { layers of } \\
\text { paying } \\
\text { Auto- } \\
\text { renewal } \\
\text { contract } \\
\text { too } \\
\text { difficult to } \\
\text { cancel }\end{array}$ & $\begin{array}{l}\text { Animation } \\
\text { lack in } \\
\text { original } \\
\text { versions }\end{array}$ & $\begin{array}{l}\text { Technical } \\
\text { problems }\end{array}$ \\
\hline & & & $\begin{array}{l}\text { Include up- } \\
\text { to-date } \\
\text { content }\end{array}$ & \\
\hline
\end{tabular}

\section{REFERENCES}

[1] Y. Zhang, The Layout, Trend, and Prospect of ShortVideo News in Mainland China, 2020 3rd International Conference on Interdisciplinary Social Sciences \& Humanities. https://webofproceedings.org/proceedings_series/E SSP/SOSHU\%202020/SOSHU20078.pdf

[2] Kaya Yurieff. TikTok is the latest social network sensation. CNN Business. November 21, 2018. 
https://edition.cnn.com/2018/11/21/tech/tiktokapp/index.html

[3] Ao Peng, Development process, Characteristic and Trend of Short Video Industry, Media Observer, issue 9, 2019, pp. 16-22.

[4] Michael Curtin, Yongli Li, iQiyi: A Guide to Changing Channels, in: From Networks to Netflix, 2018, pp. 343-353. DOI: $10.4324 / 9781315658643-$ 32

[5] H.J. Kim, S.J. Lee, A study of the competitive advantage factor of new media firm: VRIO analysis of Netflix, in: Proceedings of Symposium of the Korean Institute of communications and Information Sciences, 2016, pp. 214-216.

[6] Min Sung Kim, Eun Kim, et al., Willingness to pay for over-the-top services in China and Korea, in: Telecommunications Policy, 2017, pp. 197-207. DOI: 10.1016/j.telpol.2016.12.011

[7] Sunkyung Shin, Jooyeun Park, 2021. Factors affecting users' satisfaction and dissatisfaction of OTT services in South Korea, in: Telecommunications Policy. DOI: 10.1016/j.telpol.2021.102203

[8] Y.H. Kim, W.S. Kim, J.H. Mo, Effects of global OTT(Netflix) 's entry on terrestrial broadcaster's content investment, in: Journal of Social Sciences, 2018, pp. 387-407. DOI: 10.15820/khjss.2018.44.2.015

[9] Pirongrong Ramasoota, Abhibhu Kitikamdhorn, "The Netflix effect" in Thailand: Industry and regulatory implications, in: Telecommunications Policy, 2021. DOI: $10.1016 /$ j.telpol.2021.102156

[10] Meimaridis, Melina, Mazur, Daniela, Rios, Daniel., The Streaming Wars in the Global Periphery: A Glimpse from Brazil, in: Series(Bologna), 2020, pp. 65-76. DOI: 10.6092/issn.2421-454X/10457

[11] José A. Cordeiro, Deborah Castro, et al. "BWDAT: A research tool for analyzing the consumption of VOD content at home", Addictive Behaviors Reports, 2021, DOI: 10.1016/j.abrep.2020.100336

[12] David Pogue, "A Stream of Movies, Sort of Free", The New York Times, ISSN 0362-4331. January 25, 2007.https://www.nytimes.com/2007/01/25/technol ogy/25pogue.html.

[13] Jon Swartz, "Netflix shares close up $8 \%$ for yet another record high", MarketWatch. July 10, 2020. https://www.marketwatch.com/story/netflix-sharesclose-up-8-for-yet-another-record-high-2020-0710 .
[14] Yi Shu Ng, "Netflix takes its first steps into China, the world's hungriest streaming market", Mashable. April 26, 2017. https://mashable.com/article/netflixchina-iqiyi\#G8YL20JxXZqb.

[15] "Baidu's iQiyi Drops in Debut After IPO Raising \$2.3 Billion", Bloomberg.com. March 29, 2018. https://www.bloomberg.com/news/articles/201803-29/baidu-s-iqiyi-drops-in-trading-debut-afterraising-2-3-billion.

[16] Bernardita Calzon, "The Importance Of Financial Reporting And Analysis: Your Essential Guide", Dashboarding, Mar 17th 2021. https://www.datapine.com/blog/financialreporting-and-analysis.

[17] "Annual Meeting of Stockholders of Netflix, Inc." Netflix, Jun 3, 2021. https://ir.netflix.net/financials/annual-reports-andproxies/default.aspx

[18] "Iqiyi released 2020 Q4 and annual financial results: annual revenue of 29.7 billion operating losses narrowed significantly" Iqiyi, Feb 18, 2021. https://www.iqiyi.com/kszt/newsyyksdfsz.html

[19] Z. Xiang, Z. Schwartz, J.H. Gerdes, M.Uysal, "What can big data and text analytics tell us about hotel guest experience and satisfaction? "Int. J. Hosp. Manag., 2015, pp. 120-130. DOI https://doi.org/10.1016/j.ijhm.2014.10.013

[20] "Netflix director: $85 \%$ of new revenue comes from original content" Sina Technology. May 16, 2018. http://www.zongyijia.net/News/News_info?id=951 64.

[21] Y.H. Kim, W.S. Kim, J.H. Mo, "Effects of global OTT(Netflix) 's entry on terrestrial broadcaster's content investment ", Journal of Social Sciences, 44 (2) (2018), pp. 387-407. DOI: 10.15820/khjss.2018.44.2.015

[22] "Want to be Netflix? In addition to the difference between high-quality homemade dramas, how far is iqiyi?" Micro special science and technology classroom. May 2020. https://baijiahao.baidu.com/s?id=16678249022859 $38279 \& w f r=$ spider $\&$ for $=p c$ 